\title{
Endoscopic Band Ligation to Treat a Massive Hemorrhoidal Hemorrhage Following a Transrectal Ultrasound-Guided Prostate Biopsy
}

\author{
Nadim Mahmud, Kirk J. Wangensteen \\ Division of Gastroenterology, Department of Medicine, University of Pennsylvania Perelman School of Medicine, Philadelphia, PA, USA
}

Prostate cancer is commonly diagnosed by using a transrectal ultrasound (TRUS)-guided biopsy. Although this procedure is usually well tolerated, rarely it may be complicated by massive rectal bleeding. We report a case of a 77-year-old male who underwent a TRUS biopsy and subsequently developed recurrent episodes of rectal bleeding with syncope and anemia requiring the transfusion of multiple units of blood. A sigmoidoscopy revealed the source of the bleeding: a large hemorrhoid on the anterior wall of the rectum with an overlying ulceration. We successfully applied a band to ligate the hemorrhoid, and the patient's condition improved. To our knowledge, this case represents the first report of a successful band ligation to treat massive bleeding from a hemorrhoid that had been punctured in the course of the TRUS biopsy procedure.

Keywords: Transrectal ultrasound; Prostate biopsy; Rectal bleeding; Hemorrhage; Band ligation

\section{INTRODUCTION}

In patients undergoing screening for prostate cancer, an elevated prostate-specific antigen (PSA) or a rectal exam with concerning findings will typically lead to a prostate biopsy to evaluate for malignancy. The transrectal ultrasound (TRUS)-guided prostate biopsy is the most widely used method to obtain a tissue diagnosis $[1,2]$ and may involve between 6 and 18 core biopsy samples, depending on which protocol is used [3-5]. Although the procedure is generally well tolerated, a number of important complications may arise from this procedure that result in 30-day hospital admission rates ranging from $1.0 \%$ to $6.9 \%$, with a 2.65 -fold increased risk of hospitalization compared to the general population [6]. A retrospective analysis of 1,875 patients undergoing a TRUS-

Received: September 18, 2016 - Accepted: October 17, 2017

Correspondence to: Kirk J. Wangensteen, M.D.

Division of Gastroenterology, Department of Medicine, University of Pennsylvania, 3400 Civic Center Boulevard, PCAM 7S GI, Philadelphia, PA 19104, USA

Tel: +1-215-349-8222, Fax: +1-215-349-5914,E-mail: wkirk@upenn.edu ORCID code: https://orcid.org/0000-0001-6042-6490

(C) 2018 The Korean Society of Coloproctology

This is an open-access article distributed under the terms of the Creative Commons Attribution NonCommercial License (http://creativecommons.org/licenses/by-nc/4.0) which permits unrestricted noncommercial use, distribution, and reproduction in any medium, provided the original work is properly cited guided prostate biopsy found that the most common reasons for hospitalization were acute prostatitis $(3.8 \%)$, acute urinary retention $(2.1 \%)$, and hematuria (1.9\%) [7]. Although the overall incidence of rectal bleeding after a TRUS biopsy is reported to range from $0 \%$ to $37 \%$, severe rectal bleeding requiring hospitalization is uncommon, $0.2 \%$ according to Chiang et al. [7]. A life-threatening rectal hemorrhage requiring transfusions is rare and is limited to case reports. To our knowledge, we report the first case of successful treatment with endoscopic band ligation of a massive hemorrhoidal hemorrhage following a TRUS biopsy.

\section{CASE REPORT}

A 77-year-old male with no significant past medical history presented to our medical center's Emergency Department with symptoms of bright red blood per rectum. Two years prior, the patient had undergone a TRUS-guided prostate biopsy at an outside hospital for an elevated PSA of $7 \mathrm{ng} / \mathrm{mL}$ (normal $<4 \mathrm{ng} / \mathrm{mL}$ ) and was found to have a Gleason score of 6 . The patient elected to pursue surveillance, and in the following year, his PSA was $5 \mathrm{ng} /$ $\mathrm{mL}$. One month prior to presentation at our facility, the PSA was $6 \mathrm{ng} / \mathrm{mL}$. Four days prior to presentation, the patient had undergone a repeat TRUS-guided prostate biopsy in the other hospital's urological procedure room. No immediate complications were 


\section{Coloproctology Nadim Mahmud, et al.}

encountered, so the patient was sent home. Several hours later, he developed lightheadedness and bright red blood per rectum. Upon returning to the outside hospital, he developed syncope and was taken to their Emergency Department, where he had ongoing bright red blood per rectum. The hemoglobin was found to have decreased from a preprocedural level of $12.9 \mathrm{~g} / \mathrm{dL}$ (normal, 13.5$17.5 \mathrm{~g} / \mathrm{dL}$ ) to $9.7 \mathrm{~g} / \mathrm{dL}$. Computed tomography (CT) angiography of the abdomen and pelvis showed active bleeding in the rectum. The patient was observed, and his bleeding appeared to self-resolve. He was not given blood products and was discharged on the next day, 3 days prior to his presentation at our medical center.

On the evening of the fourth day postprocedure, the patient again developed lightheadedness and bright red blood per rectum. He was brought to our Emergency Department for further evaluation. He had not taken any medications. His temperature was $36.3^{\circ} \mathrm{C}$, his heart rate 110 per minute, his blood pressure $109 / 62 \mathrm{mmHg}$, and his oxygen saturation was $96 \%$ on room air. On physical examination, he appeared diaphoretic and pale; no abdominal tenderness was found. Laboratory studies revealed a hemoglobin level of $7.7 \mathrm{~g} / \mathrm{dL}$. The platelets, prothrombin time (PT), and partial thromboplastin time were within their normal ranges. CT angiography of the abdomen and pelvis showed active bleeding in the anterior rectum. Over the next 12 hours, the patient had eight episodes of large-volume bright red blood per rectum and clots. He received seven units of blood and 2 units of fresh frozen plasma. Although the patient was alert and oriented at the time of presentation, he subsequently developed syncope with poor arousability and was intubated in our intensive care unit for airway protection. A 500-mL tap water enema was administered, and he underwent flexible sigmoidoscopy.

On sigmoidoscopy, bright red blood and clots were noted from the rectum to $15 \mathrm{~cm}$ of intubation, where normal mucosa was vi- sualized. On the anterior aspect of the rectum, at 1 to $2 \mathrm{~cm}$ from the dentate line, an approximately $3-\mathrm{mm}$ ulcerated lesion was noted overlying a raised lesion that was pulsatile (Fig. 1). Six mililiters of $0.0001 \%$ epinephrine solution was injected circumferentially around this lesion, with immediate brisk bleeding noted at the injection sites. Although clipping and/or cautery were initially considered for hemostasis, on retroflexion, the lesion was apparently contiguous with what appeared to be a large internal hemorrhoid (Fig. 2). As such, band ligation (Speedband Superview Super 7, Boston Scientific, Marlborough, MA, USA) was performed using a single band around the site of the ulcerated lesion, with successful hemostasis being achieved (Fig. 3). After the proce-

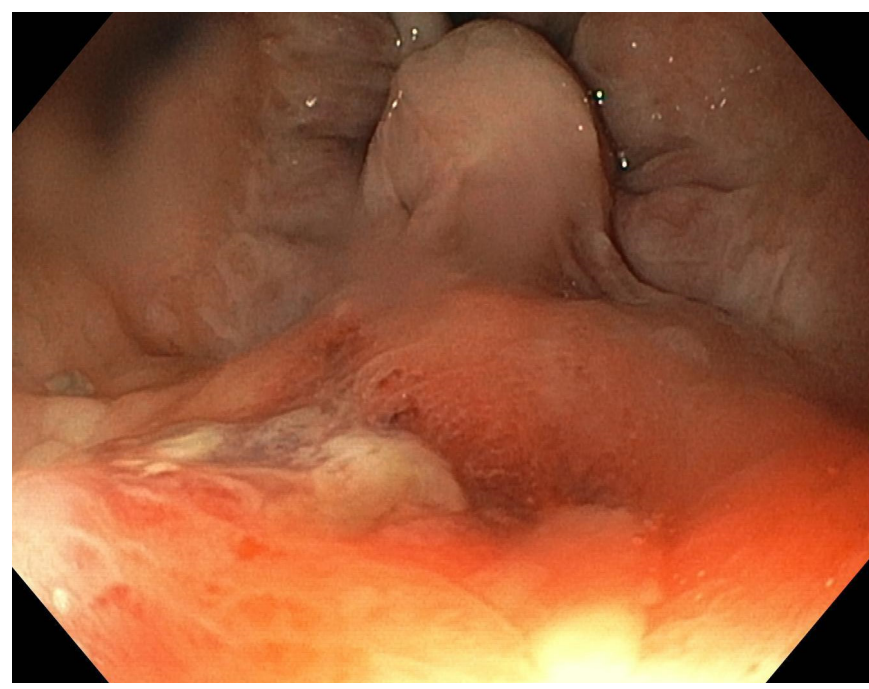

Fig. 2. A retroflexed view of the internal hemorrhoidal column extending to the ulcerated lesion.
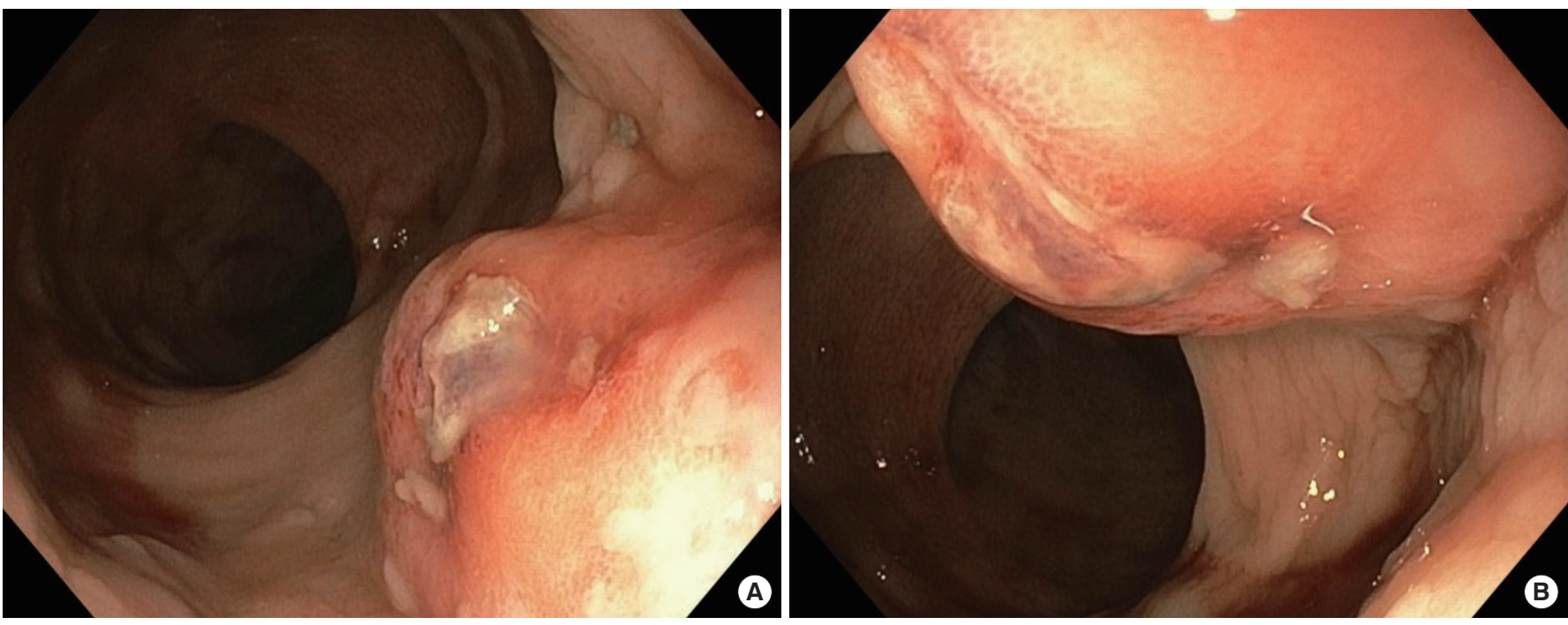

Fig. 1. (A, B) Immediately proximal to the anal verge, a 3-mm ulcerated lesion overlying a dilated, pulsatile, vascular structure was noted. 

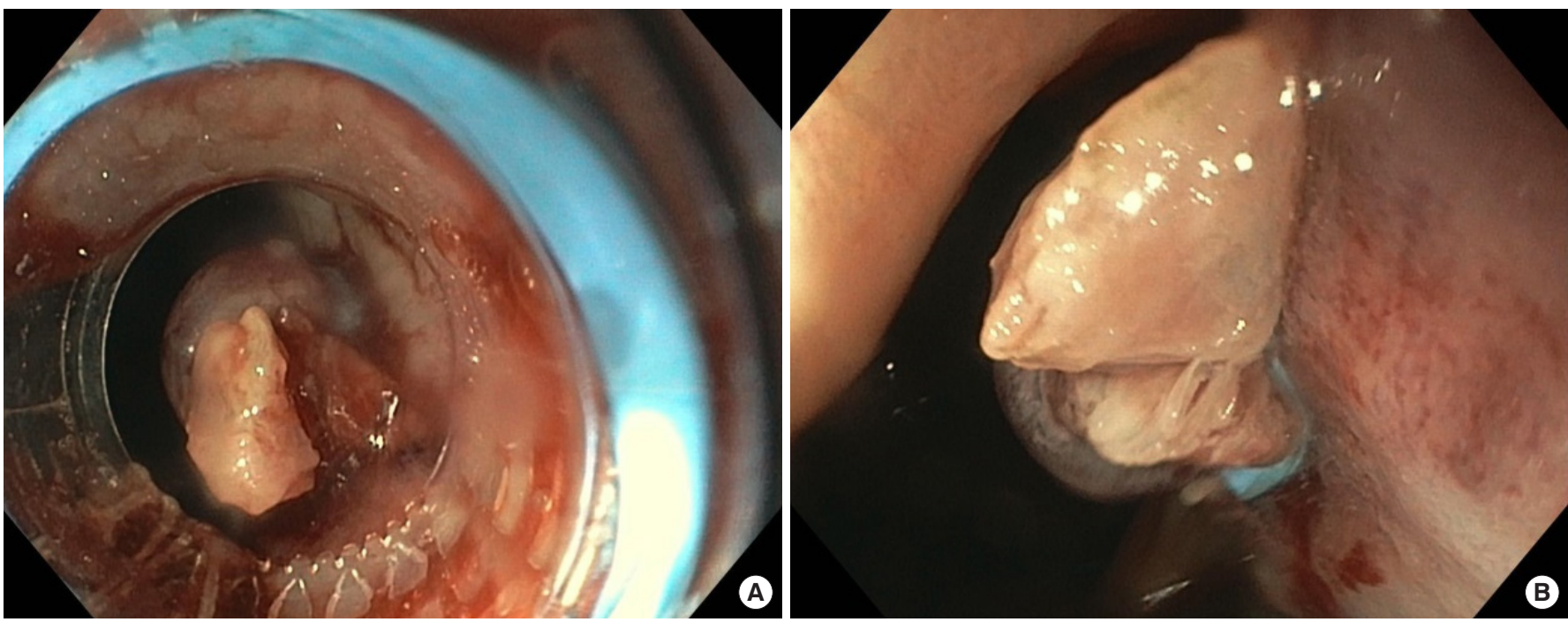

Fig. 3. (A, B) Successful band ligation of the internal hemorrhoid.

Table 1. Reported cases of rectal bleeding requiring transfusion after a transrectal ultrasound-guided prostate biopsy

\begin{tabular}{|c|c|c|c|c|c|}
\hline Study & No. of patients & Bleeding source $(n)$ & Procedure & Bowel preparation & Method of hemostasis \\
\hline \multirow[t]{2}{*}{ Brullet et al. [8] } & 5 & Nonbleeding visible vessel (1) & Colonoscopy & Unprepped & $\begin{array}{l}\text { Endoscopic epinephrine + polidocanol } \\
\text { injection }\end{array}$ \\
\hline & & Anterior rectal wall bleeding (4) & Colonoscopy & Unprepped & Endoscopic epinephrine injection \\
\hline \multirow[t]{2}{*}{ Strate et al. [9] } & 2 & Rectal wall puncture site (1) & Flexible sigmoidoscopy & Oral GoLytely rapid prep & Endoscopic band ligation \\
\hline & & $\begin{array}{l}\text { Focal bleeding sitewith adherent } \\
\text { clot (1) }\end{array}$ & $\begin{array}{l}\text { t Flexible sigmoidoscopy } \\
\text { followed by colonoscopy }\end{array}$ & $\begin{array}{l}\text { Fleet's enema } \times 2 \text { followed } \\
\text { by oral GoLytely rapid prep }\end{array}$ & Endoscopic epinephrine injection \\
\hline Katsinelos et al. [10] & 1 & $\begin{array}{l}\text { Two focal bleeding points in } \\
\text { anterior rectal wall }\end{array}$ & Colonoscopy & Unprepped & Endoscopic clipping \\
\hline Ozveren et al. [11] & 1 & $\begin{array}{l}\text { Pulsatile bleeding from rectal } \\
\text { mucosa }\end{array}$ & Flexible sigmoidoscopy & Unprepped & $\begin{array}{l}\text { Endoscopic epinephrine followed by } \\
\text { clipping }\end{array}$ \\
\hline Pacios et al. [12] & 1 & Anterior rectal wall bleeding & Colonoscopy & Not specified & $\begin{array}{l}\text { Endoscopic epinephrine + ethanol } \\
\text { injection }\end{array}$ \\
\hline Braun et al. [13] & 1 & Rectal arterial oozing & $\begin{array}{l}\text { Colonoscopy followed by } \\
\text { flexible sigmoidoscopy }\end{array}$ & Not specified & Endoscopic epinephrine injection \\
\hline Ustündağ et al. [14] & 1 & $\begin{array}{l}\text { Visible vessel on anterior rectal } \\
\text { wall }\end{array}$ & Colonoscopy & Not specified & Endoscopic aethexysclerol injection \\
\hline Dauleh et al. [15] & 1 & $\begin{array}{l}\text { Three focal bleeding points in } \\
\text { anterior rectal wall }\end{array}$ & Proctoscopy & Not specified & Thermocoagulation \\
\hline Khan et al. [16] & 1 & Presumed internal hemorrhoid & Flexible sigmoidoscopy & Not specified & $\begin{array}{l}\text { Inflated Foley balloon tamponade } \\
\text { (nonendoscopic) }\end{array}$ \\
\hline Gonen and Resim [17] & 1 & Anterior rectal wall bleeding & Colonoscopy & Fleet's enema & $\begin{array}{l}\text { Inflated condom tamponade } \\
\text { (nonendoscopic) }\end{array}$ \\
\hline
\end{tabular}

dure, the patient had no further signs of bleeding and showed stable hemoglobin levels on serial testing. He was successfully extubated within 24 hours and was discharged 5 days later.

\section{DISCUSSION}

Although rare, life-threatening rectal hemorrhage can occur following a TRUS-guided prostate biopsy. In our review of the litera- 
ture, we found a total of 15 reported cases of a rectal hemorrhage requiring red cell transfusion (Table 1) [8-17]. Two of the cases were ultimately managed using a rectal balloon tamponade. In the remainder, hemostasis was achieved through endoscopic methods, including epinephrine injection alone, sclerosant injection alone, epinephrine plus sclerosant injection, thermocoagulation, endoclipping, and band ligation. The majority of cases noted bleeding from focal puncture sites along the anterior rectal wall. Only 1 previous case posited internal hemorrhoid puncture as the cause of the hemorrhage; that case was managed successfully using a balloon tamponade. To our knowledge, this is the first case of hemorrhoidal bleeding caused by a puncture during a TRUS biopsy procedure being successfully managed by using band ligation.

In patients undergoing an endoscopic evaluation of a rectal hemorrhage after a TRUS biopsy, the practices regarding bowel preparation vary. In our estimation, a complete colonoscopy preparation is probably unnecessary and may delay therapy, as the bleeding is overwhelmingly likely to be immediately proximal to the anal verge, as in our case. Prior to sigmoidoscopy, we elected to perform tap-water enemas primarily to clear blood and clots that might otherwise have been difficult to irrigate and aspirate endoscopically. On flexible sigmoidoscopy, the anterior wall was found to have an apparent hemorrhoid with a focal ulcerated lesion. We presume that a core biopsy had been obtained through this internal hemorrhoid, which resulted in severe, recurrent hemorrhage, despite the lack of anti-platelet or anticoagulant agents or other known coagulopathy.

In evaluating the bleeding risk of a TRUS biopsy, one must consider the anorectal vascular anatomy. Branches of the middle and the inferior rectal arteries supply the distal rectum, and a rich arteriovenous hemorrhoidal plexus lines the anal canal. In patients with hemorrhoids, this plexus may be substantially dilated, increasing the theoretical risk of puncture or shearing during a TRUS biopsy, especially if a higher number of cores are obtained [18]. As such, caution should be taken in performing TRUSguided prostate biopsies in patients with a known history of hemorrhoids. At minimum, a targeted history and rectal exam should be performed prior to the planned TRUS biopsy. If concern for large hemorrhoids exists, especially in a patient on antiplatelet and/or anticoagulant agents, consideration should be given to a transperineal biopsy approach [19]. We recommended that our patient avoid TRUS biopsy procedures in the future. In summary, although the literature suggests that numerous modalities may achieve hemostasis after massive TRUS biopsy bleeding, our case demonstrates that band ligation can be an extremely effective and well-tolerated treatment.

\section{CONFLICT OF INTEREST}

No potential conflict of interest relevant to this article was reported.

\section{REFERENCES}

1. Boczko J, Messing E, Dogra V. Transrectal sonography in prostate evaluation. Radiol Clin North Am 2006;44:679-87, viii.

2. Hodge KK, McNeal JE, Stamey TA. Ultrasound guided transrectal core biopsies of the palpably abnormal prostate. J Urol 1989; 142:66-70.

3. Hodge KK, McNeal JE, Terris MK, Stamey TA. Random systematic versus directed ultrasound guided transrectal core biopsies of the prostate. J Urol 1989;142:71-4.

4. Cash H, Maxeiner A, Stephan C, Fischer T, Durmus T, Holzmann $\mathrm{J}$, et al. The detection of significant prostate cancer is correlated with the Prostate Imaging Reporting and Data System (PI-RADS) in MRI/transrectal ultrasound fusion biopsy. World J Urol 2016; 34:525-32.

5. Lee A, Chia SJ. Contemporary outcomes in the detection of prostate cancer using transrectal ultrasound-guided 12-core biopsy in Singaporean men with elevated prostate specific antigen and/or abnormal digital rectal examination. Asian J Urol 2015;2:187-93.

6. Loeb S, Carter HB, Berndt SI, Ricker W, Schaeffer EM. Complications after prostate biopsy: data from SEER-Medicare. J Urol 2011; 186:1830-4.

7. Chiang IN, Chang SJ, Pu YS, Huang KH, Yu HJ, Huang CY. Major complications and associated risk factors of transrectal ultrasound guided prostate needle biopsy: a retrospective study of 1,875 cases in taiwan. J Formos Med Assoc 2007;106:929-34.

8. Brullet E, Guevara MC, Campo R, Falcó J, Puig J, Prera A, et al. Massive rectal bleeding following transrectal ultrasound-guided prostate biopsy. Endoscopy 2000;32:792-5.

9. Strate LL, O'Leary MP, Carr-Locke DL. Endoscopic treatment of massive rectal bleeding following prostate needle biopsy. Endoscopy 2001;33:981-4.

10. Katsinelos P, Kountouras J, Dimitriadis G, Chatzimavroudis G, Zavos C, Pilpilidis I, et al. Endoclipping treatment of life-threatening rectal bleeding after prostate biopsy. World J Gastroenterol 2009;15:1130-3.

11. Ozveren B, Türkeri L. Massive rectal bleeding after prostate biopsy controlled by endoclipping in a patient using acetylsalicylic acid. Can Urol Assoc J 2013;7:E442-4.

12. Pacios E, Esteban JM, Breton ML, Alonso MA, Sicilia-Urbán JJ, Fidalgo MP. Endoscopic treatment of massive rectal bleeding following transrectal ultrasound-guided prostate biopsy. Scand J Urol Nephrol 2007;41:561-2.

13. Braun KP, May M, Helke C, Hoschke B, Ernst H. Endoscopic therapy of a massive rectal bleeding after prostate biopsy. Int Urol Nephrol 2007;39:1125-9.

14. Ustündağ Y, Yeşilli C, Aydemir S, Savranlar A, Yazicioğlu K. A life-threatening hematochesia after transrectal ultrasound-guided prostate needle biopsy in a prostate cancer case presenting with lymphedema. Int Urol Nephrol 2004;36:397-400.

15. Dauleh MI, Byrne DJ. Severe bleeding following transrectal Trucut prostatic biopsy. Scand J Urol Nephrol 1996;30:153-4. 
16. Khan SA, Hu KN, Marder C, Smith NL. Hemorrhoidal bleeding following transrectal prostatic biopsy. Etiology and management. Dis Colon Rectum 1982;25:817-9.

17. Gonen M, Resim S. Simplified treatment of massive rectal bleeding following prostate needle biopsy. Int J Urol 2004;11:570-2.

18. Ghani KR, Dundas D, Patel U. Bleeding after transrectal ultrasonography-guided prostate biopsy: a study of 7-day morbidity af- ter a six-, eight- and 12-core biopsy protocol. BJU Int 2004;94: 1014-20.

19. Sheikh M, Hussein AY, Kehinde EO, Al-Saeed O, Rad AB, Ali $\mathrm{YM}$, et al. Patients' tolerance and early complications of transrectal sonographically guided prostate biopsy: prospective study of 300 patients. J Clin Ultrasound 2005;33:452-6. 